\title{
Diabetes and cardiovascular disease: from evidence to clinical practice - position statement 2014 of Brazilian Diabetes Society
}

\author{
Marcello Casaccia Bertoluci ${ }^{1}$, Augusto Pimazoni-Netto ${ }^{2 *}$, Antonio Carlos Pires ${ }^{3}$, Antonio Eduardo Pesaro ${ }^{4}$, \\ Beatriz D Schaan ${ }^{1}$, Bruno Caramelli ${ }^{5}$, Carisi Anne Polanczyk ${ }^{1}$, Carlos Vicente Serrano Júnior ${ }^{6}$, Danielle M Gualandro ${ }^{5}$, \\ Domingos Augusto Malerbi ${ }^{7}$, Emilio Moriguchi ${ }^{1}$, Flavio Antonio de Oliveira Borelli ${ }^{8}$, João Eduardo Nunes Salles ${ }^{9}$, \\ José Mariani Júnior ${ }^{9}$, Luis Eduardo Rohde ${ }^{1}$, Luis H Canani ${ }^{1}$, Luiz Antonio Machado Cesar ${ }^{5}$, Marcos Tambascia ${ }^{10}$, \\ Maria Tereza Zanella ${ }^{2}$, Miguel Gus ${ }^{11}$, Rafael Selbach Scheffel ${ }^{11}$ and Raul Dias dos Santos ${ }^{5}$
}

\begin{abstract}
There is a very well known correlation between diabetes and cardiovascular disease but many health care professionals are just concerned with glycemic control, ignoring the paramount importance of controlling other risk factors involved in the pathogenesis of serious cardiovascular diseases. This Position Statement from the Brazilian Diabetes Society was developed to promote increased awareness in relation to six crucial topics dealing with diabetes and cardiovascular disease: Glicemic Control, Cardiovascular Risk Stratification and Screening Coronary Artery Disease, Treatment of Dyslipidemia, Hypertension, Antiplatelet Therapy and Myocardial Revascularization. The issue of what would be the best algorithm for the use of statins in diabetic patients received a special attention and a new Brazilian algorithm was developed by our editorial committee. This document contains 38 recommendations which were classified by their levels of evidence (A, B, C and D). The Editorial Committee included 22 specialists with recognized expertise in diabetes and cardiology.
\end{abstract}

Keywords: Diabetes, Glicemic control, Cardiovascular risk stratification, Screening coronary artery disease, Treatment of dyslipidemia, Hypertension, Antiplatelet therapy, Myocardial revascularization

\section{Introduction}

This Position Statement is a review based on the best currently available scientific evidence to guide the prevention and management of cardiovascular disease in patients with diabetes. The document was developed by endocrinologists and cardiologists gathered in the Group of Experts on Diabetes and Cardiovascular Risk, which contributed significantly to the development of this document, formatted into practical recommendations regarding management of cardiovascular disease in these patients.

This paper innovates by reviewing the concept of equivalence of cardiovascular risk in patients with diabetes in light of recent evidences suggesting the presence

\footnotetext{
*Correspondence: pimazoni@uol.com.br

¿Universidade Federal de São Paulo, São Paulo, Brazil

Full list of author information is available at the end of the article
}

of lower-risk subgroups within this population. On the other hand, targets of LDL-c on treatment with statins are no longer recommended and the suggestion to make therapeutic decisions based on the stratification of cardiovascular risk by use of the calculator UKPDS cardiovascular risk assessment is now enforced.

Also incorporated, now in a more defined way, the use of calcium score in more specific situations regarding the use of statins. It was also included an update on the recommendations for the treatment of hypertension, for the use of antiplatelet and finally an update on indications for myocardial revascularization exclusively in patients with diabetes.

The Brazilian Diabetes Society (SBD = Sociedade Brasileira de Diabetes) hopes that this review will be useful in clinical practice targeting an increased quality of care for patients with diabetes. 


\section{Methodology}

This Position Statement rated levels of evidence according to Table 1, and for each recommendation, the evidence is presented below.

Originally, the members of the editorial board defined the topics considered relevant and that required positioning by SBD. Thereafter a search of the literature was performed to select the most important studies. It was then drafted a preliminary manuscript with the respective levels of evidence which underwent several rounds of discussion among committee members for review and suggestions. The manuscript then returned to the chief editor for tweaking and unifying editorial style. The manuscript was subsequently subjected to further revisional rounds by some members of the committee in seeking a consensus position and after this phase it was forwarded for final editoring and then submitted for publication.

\section{Recommendations}

The recommendations of this Position Statement of the Brazilian Diabetes Society will be divided into six modules, namely:

- Module 1: Glicemic Control

- Module 2: Cardiovascular Risk Stratification and Coronary Disease Screening

- Module 3: Treatment of Dyslipidemia

- Module 4: Treatment of Hypertension

- Module 5: Antiplatelet Therapy

- Módulo 6: Myocardial Revascularization

- References

The numbered references in the texts of each module are described at the end of the full text.

\section{Module 1: glycemic control}

\section{In adult patients with diabetes mellitus, target HbA1c of approximately $7.0 \%$ is recommended. [Level A]}

Table 1 Levels and descriptions of evidence

\begin{tabular}{cc}
\hline Levels of evidence & Description \\
\hline Level A & $\begin{array}{r}\text { Direct evidence from meta-analysis or } \\
\text { randomized clinical trials }\end{array}$ \\
Level B & $\begin{array}{c}\text { Evidence from large observational studies and } \\
\text { indirect evidence analysis of pre-specified subgroup } \\
\text { of randomized clinical trials or meta-analysis with } \\
\text { low heterogeneity. }\end{array}$ \\
Level C & Evidence from small studies, non-randomized \\
or open & Expert opinion
\end{tabular}

Summary of evidence:

- The DCCT [1] and UKPDS [2,3] classic studies conducted in subjects with type 1 and type 2 diabetes have demonstrated convincingly that intensive glycemic control (HbA1c 7.0\%) reduces chronic microvascular complications [4] and, in the long-term, can also reduce the occurrence of non-fatal acute myocardial infarction [5,6]. Evidence from 3 large clinical trials in patients with type 2 diabetes - ADVANCE [7], ACCORD [8] and VADT [9], which evaluated more-intensive compared to less-intensive glycemic targets, showed only reduced microvascular, but not macrovascular complications. Meta-analysis that included these studies showed marginal reduction in the risk of myocardial infarction with more intensive glycemic control, but with an increase in the number of severe hypoglycemias [10]. Thus, the target for the treatment of hyperglycemia in type 2 diabetes is to achieve A1C levels of $\sim 7 \%$, and specific glycemic goals are: fasting glucose between $70-130 \mathrm{mg} / \mathrm{dL}$ and postprandial glucose $<180 \mathrm{mg} / \mathrm{dL}$ [11].

2. In elderly patients with co-morbidities that significantly limit life expectancy, in whom the risk of hypoglycemia is even more harmful, it is acceptable to seek an A1C target level of up to 7.9\%. [Level B]

\section{Summary of evidence:}

- Less stringent target (A1C 7.0 to 7.9\%) should be considered in patients with a history of frequent episodes of hypoglycemia, late-onset diabetes, micro or macrovascular advanced disease or when there is difficulty in maintaining good glycemic control, despite the association of various medicines. In ACCORD [8] study, although there was a reduction in cardiovascular morbidity, there was also an increase in mortality with more intensive control. A meta-analysis showed only marginal reduction in the risk of myocardial infarction with intensive glucose control, but with an increase in the number of severe hypoglycemia [10]. Data from observational studies also reinforce the need to target $A 1 C$ to less stringent levels, showing that the lowest risk of mortality occurs around an A1C of 7.5\% [12]. The absolute benefit obtained with intensive treatments in 5 years is modest: the number needed to treat (NNT) to prevent one event is 140 for ischemic heart disease, 768 for stroke, 272 for mono-ocular blindness and 
627 for ESRD. In turn, the number needed to harm (NNH) is 328 for total mortality and 21 for severe hypoglycemia [10,13]. Furthermore, the maintenance of $A 1 C$ from values below $8 \%$ is also less cost-effective [14].

\section{In patients hospitalized for acute myocardial infarction (AMI), it is suggested to maintain blood glucose between 130 and 180-200 mg/dL using continuous intravenous insulin. [LEVEL B]}

Summary of evidence:

- Three randomized clinical trials have evaluated the role of glycemic control in the incidence of cardiovascular events after an acute myocardial infarction (AMI) in patients with diabetes. The first was the DIGAMI [15] study, in which 620 patients with DM and AMI were included. Treatment strategies were: infusion of insulin and glucose IV in the first 24 hours with a glycemic target of 126-196 $\mathrm{mg} / \mathrm{dL}$, followed by subcutaneous administration of insulin four times daily for 3 months vs. insulin therapy only when clinically indicated. The group using insulin in the acute phase had better glycemic control during hospitalizationat 3 months and at 1 year, and also had lower mortality rates at 1 and 3.4 years of follow-up.

- The DIGAMI-2 [16] compared 3 groups: insulin during hospitalization followed by outpatient use, use of insulin only during hospitalization and usual treatment throughout the period. Glycemic control was similar between groups as well as cardiovascular outcomes.

- HI-5 [17] study included 240 patients with a history of diabetes and glucose $\geq 140 \mathrm{mg} / \mathrm{dL}$ on hospital admission for AMI, who were randomized to strict glycemic control (target 72-180 $\mathrm{mg} / \mathrm{dL}$ ) with insulin plus intravenous glucose infusion for at least 24 hours or conventional therapy. Subsequently, patients were managed by their physician, with a recommendation to maintain A1C $<7 \%$. The rates of in-hospital mortality did not differ between groups.

\footnotetext{
4. In patients in the immediate postoperative cardiac surgery, it is recommended to maintain blood glucose between 120 and $150 \mathrm{mg} / \mathrm{dL}$ using continuous intravenous insulin. [LEVEL A]
}

Summary of evidence:

- Hyperglycemia before or after cardiac surgery is associated with a higher risk of complications such as death, prolonged mechanical ventilation, renal failure, stroke and deep sternal infection [18,19].

- The Portland Diabetes Project was an observational study that evaluated the relationship between hyperglycemia and adverse outcomes of cardiac surgery in patients with diabetes. It consisted of using continuous intravenous insulin, adjusted by frequent blood glucose tests based on standardized protocol conducted by nurses, with target glycemia $150-200 \mathrm{mg} / \mathrm{dL}$.

Subsequently, this blood glucose target has changed to 125-175 $\mathrm{mg} / \mathrm{dL}$ and then to 100 to $150 \mathrm{mg} / \mathrm{dL}$, because studies in other scenarios were identifying the need for normalization of blood glucose reduction outcomes. The use of this protocol compared with the use of subcutaneous insulin according to glucose levels (historical control) was associated with reduced rates of infection [20] and death in about 50\% [21].

- A randomized clinical trial with patients in the surgical intensive coronary unit (ICU), (mostly in post-cardiac surgery (63\%) and 13\% with diabetes) showed benefit with intensive glycemic control (insulin infusion for glycemic target $80-110 \mathrm{mg} / \mathrm{dL}$ vs. 180-200 $\mathrm{mg} / \mathrm{dL}$ ) in mortality, infection, acute renal failure with hemodialysis, blood transfusion, and polyneuropathy in critically ill patients, but at the expense of higher rates of hypoglycemia [22].

- However, multicenter clinical trial with larger number of patients (Nice Sugar Study) conducted in medical and surgical ICUs (63\% and 37\% of patients, respectively), 20\% with a history of diabetes, showed that intensive glycemic control (target $<108 \mathrm{mg} / \mathrm{dL}$ ) vs. usual control (140 to $180 \mathrm{mg} / \mathrm{dL}$ ) resulted in increased mortality and also higher rates of hypoglycemia [23].

- Meta-analysis including data from NICE SUGAR study, evaluating separately results obtained from clinical and surgical ICUs, showed that tight glucose control offers no reduction of mortality in patients in clinical ICU, but may have benefit in surgical patients when target blood glucose is below $150 \mathrm{mg} / \mathrm{dL}$ [24]. In a small randomized clinical trial comparing two recent glycemic targets (90-120 mg/dL vs. $120-180 \mathrm{mg} / \mathrm{dL}$ ) in patients with diabetes undergoing coronary artery bypass grafting, a more stricted blood glucose control provided no benefit and even increased the risk of hypoglycemia [25]. 
Module 2: cardiovascular risk stratification and screening of coronary artery disease

5. It is recommended that patients with type 2 diabetes without a history of cardiovascular disease have their cardiovascular risk stratified annually by the UKPDS risk-calculator, using the outcome: (CHD - Coronary Heart Disease) in 10 years. Through this tool, patients should be divided into low risk (<10\% in 10 years), intermediate risk (10-20\% in 10 years) and high risk (>20\% in 10 years). [LEVEL D]

Summary of evidence:

- The UKPDS calculator was validated from a multiethnic population of the United Kingdom, originating from the UKPDS study, with 4,540 participants with type 2 diabetes between 25-65 years of age without a prior history of myocardial infarction, angina or heart failure [26]. The calculator has its best performance in the range of intermediate risk, with low levels of underestimation (13\%), being higher than the overall risk scores developed for the general population like the Framingham score, if applied to a population with diabetes [27].

Figure 1 shows the screen of the UKPDS calculator for the assessment of cardiovascular risk, taking into account the following parameters: age, duration of diabetes, sex, presence or absence of atrial fibrillation, ethnicity, presence or absence of smoking, A1C level, systolic blood pressure, total cholesterol and HDL cholesterol. With the inclusion of these data by the operator, this tool calculates the 10-year risk of occurrence of fatal and nonfatal CHD and fatal and nonfatal stroke (Figure 1).

This calculator can be downloaded without charge from the following address:

http://www.dtu.ox.ac.uk/riskengine/download.php

6. In patients with diabetes and cardiovascular risk assessed as an intermediary by the UKPDS calculator, we suggest performing the evaluation of coronary calcium score (CAC) in order to reclassify to low risk when the score is less than 10 or intermediate/high risk when more than 10, when available. [LEVEL A]

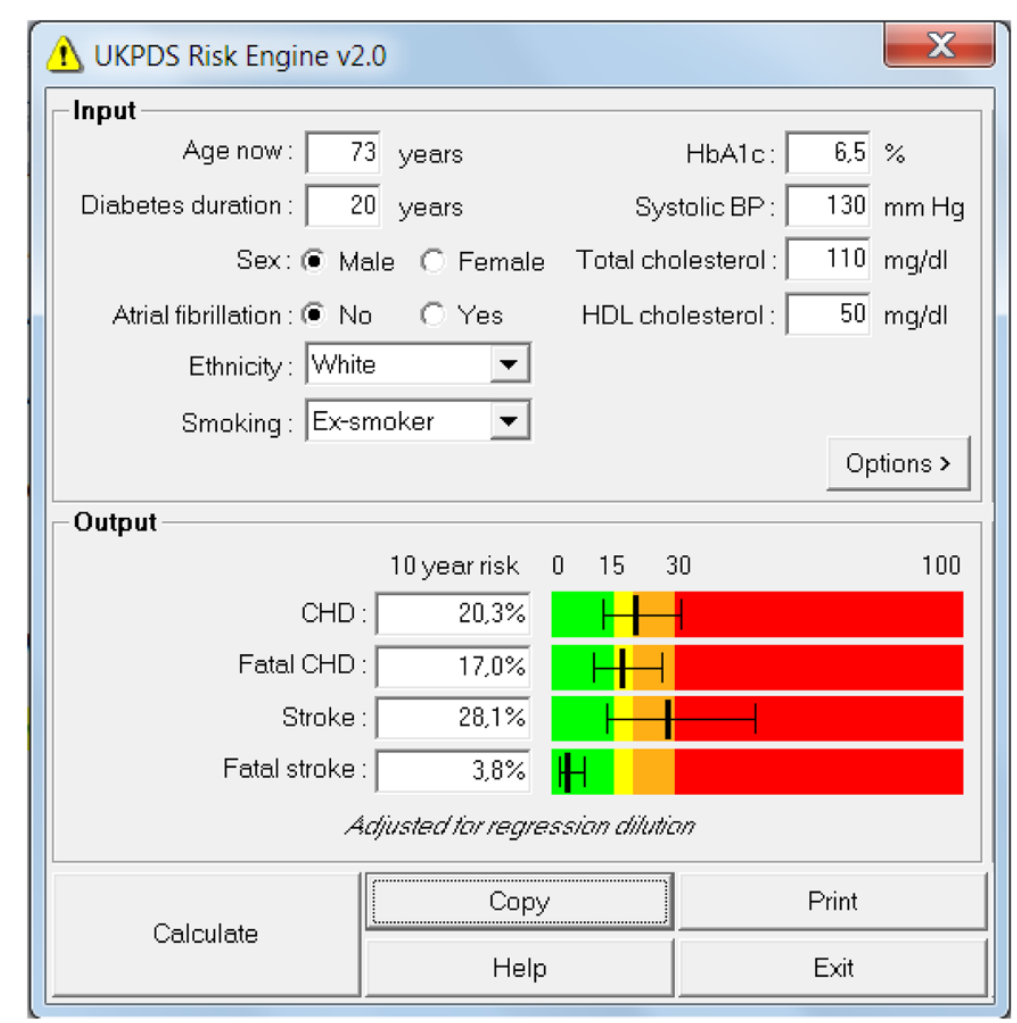

Figure 1 Example of calculating cardiovascular risk with the use of a UKPDS calculator, considering the parameters provided. 
Summary of evidence:

- The coronary artery score (CAC) proved to be a good identifier of low-risk sub-population of patients with diabetes. A meta-analysis of 8 observational studies in 6,521 patients with diabetes with a mean follow-up of 5.2 years, comparing $C A C<10$ vs. $>10$, showed a relative risk of death from all causes or cardiovascular events in the group $>10,5.47$ times higher (95\% CI 2.59 to 11.53). For patients with $C A C<10$, post-test probability of a primary endpoint was $1.8 \%$, representing a reduction of 6.6 times from the pre-test probability. The CAC $<10$ result was present in $28.5 \%$ of patients with diabetes. Given the global prevalence of diabetes of 346 million, these data suggest that 86.5 million people with diabetes may have low cardiovascular risk [28]. A re-analysis of Jupiter and the MESA study [29] showed that in the general population, $C A C=0$ corresponds to a cardiovascular event rate of 0.8 per 1000 person-years.

7. It is recommended to conduct an annual electrocardiogram for screening of coronary heart disease in patients with type 2 diabetes. [LEVEL D]

8. In asymptomatic diabetic patients under 75 years old, without rest ECG abnormalities and without previous positive stress testing, it is recommended not to perform universal screening tests for coronary disease with induction of myocardial ischemia. [LEVEL A]

Summary of evidence:

- The Detection of Ischemia in Asymptomatic Diabetics (DIAD) [30] evaluated 1,123 participants with type 2 diabetes without symptoms of coronary artery disease, randomized to screening with induction of ischemia test (myocardial perfusion adenosine stress $(n=562)$ or no screening $(n=561)$. Patients with evidence of cardiovascular disease or changes in the resting electrocardiogram were excluded from the protocol. Patients with a mean age of 61 years, duration of diabetes $>8$ years and mean A1C of $7.1 \%$ were included. The cumulative rate of cardiac events (nonfatal myocardial infarction and cardiovascular death) was lower than expected, occurring in $2.9 \%$ of patients in the follow-up of 4.8 years. In total, only 15 cardiac events occurred among the screened patients and 17 among nonscreened (OR 0.88, 95\% CI 0.44 to 1.88, $p=0.73$ ).
While screening has not implicated in a significant difference in clinical outcomes, patients with moderate to large myocardial perfusion defects had higher rates of cardiac events (OR 6.3, 95\% CI 1.9 to 20.1, $p=0.001$ ). A sub-analysis of 5 years following this same study [31] has suggested that the majority of enrolled patients were classified as intermediate or high cardiovascular risk. However, the annual risk of cardiac events in these patients remained low and was not altered by the strategy of screening for inducible ischemia, so the conclusion is that the screening of myocardial ischemia does not reduce the rate of cardiac events in patients with asymptomatic diabetes.

9. It is recommended to assess myocardial ischemia in patients with cardiovascular symptoms or with evidence of atherosclerotic disease in other vascular sites (peripheral vascular disease, carotid bruit, transient ischemic stroke or previous episodes, or presence of $Q$ waves on resting ECG). [LEVEL D]

10. The treadmill stress test is recommended as initial test for most patients who present indication for the investigation, excepting those who are unable to walk, those with resting ECG showing changes that hinder the interpretation of the test, or those with contraindications for the test. [LEVEL D]

Module 3: treatment of dyslipidemia
11. Patients with diabetes and a prior history of cardiovascular events (myocardial infarction, stroke, coronary revascularization, atherosclerotic disease of carotid, renal or peripheral arteries and the aorta) should begin intensive treatment with statins. [LEVEL A]

Summary of evidence:

- Statins have proven to reduce the risk of cardiovascular events in patients with diabetes and a previous history of vascular events. A meta-analysis of 14 trials including 18,686 patients with diabetes showed that treatment with statins reduces proportionately the incidence of vascular events by $20 \%$ for each 
$39 \mathrm{mg} / \mathrm{dL}$ reduction of $L D L-c$ in 5 years and the reductions are similar for major coronary events, stroke and need for revascularization [32].

12. In patients with diabetes and confirmed cardiovascular disease, it is recommended to reduce $L D L-c$ at least $50 \%$ of the baseline values with statins at the highest tolerated doses. Alternatively it is reasonable to reduce LDL-c below $70 \mathrm{mg} / \mathrm{dL}$ with statins. [LEVEL B]

Summary of evidence:

- A comparison between intensive vs moderate statin treatment was evaluated in a meta-analysis of 5 randomized trials with 39,612 individuals, where 5,639 (19\%) had diabetes, and 59\% had prior vascular disease, with a mean follow-up of 5.1 years [33]. Intensive treatment was defined as a reduction of $20 \mathrm{mg} / \mathrm{dL} L \mathrm{LL}-\mathrm{c}$ beyond the result obtained by moderate treatment with the use of higher power statins. The results showed $15 \%$ reduction in major vascular events (95\% CI 11-18, $p<0.0001$ ), $13 \%$ in coronary death (95\% CI 7-19, $p<0.0001$ ), 19\% in coronary artery myocardial (95\% CI 15-24 $p<0.0001)$ and $16 \%$ in stroke (95\% CI 5-26, $p=0.005)$. Intensive treatment promoted a $20 \%$ reduction in $L D L-c$ beyond the moderate treatment, while the moderate treatment promoted a decrease of $30 \%$ compared to placebo. Thus, there was an overall $50 \%$ reduction in events with intensive treatment compared to placebo. Although this is an indirect evidence, based in subgroup analysis of diabetic patients included in the meta-analysis, the absence of heterogeneity makes it plausible to be applied to patients with DM in secondary prevention.

- A pre-specified subgroup analysis of the Treat to New Targets (TNT) study, which included 1,501 patients with diabetes and coronary artery disease [34], compared the treatment with atorvastatin $80 \mathrm{mg}$ vs. atorvastatin $10 \mathrm{mg}$ for 4.9 years in cardiovascular outcomes. The study showed a significant reduction in any cardiovascular events and strokes in patients with a dose of $80 \mathrm{mg}$. Patients taking $10 \mathrm{mg}$ maintained an average level of $L D L-c$ of $96 \mathrm{mg} / \mathrm{dL}$, while those using $80 \mathrm{mg} /$ day reached $77 \mathrm{mg} / \mathrm{dL}$. Thus, the use of a target LDL-c around $70 \mathrm{mg} / \mathrm{dL}$ showed additional benefit. This committee considered that obtaining the target of $70 \mathrm{mg} / \mathrm{dL}$ is quite similar to a $50 \%$ reduction in baseline LDL-C in the great majority of cases, and therefore may alternatively be used as a target to facilitate treatment adherence.
13. It is recommended that patients with $L D L-c>$ $190 \mathrm{mg} / \mathrm{dL}$ receive statin treatment regardless of having or not a previous cardiovascular event, with the goal of a $50 \%$ reduction in cholesterol levels. [LEVEL D]

Summary of evidence:

- Although most of the clinical trials do not include patients with $L D L$ above $190 \mathrm{mg} / \mathrm{dL}$, indirect evidence from several clinical trials shows that every $39 \mathrm{mg} / \mathrm{dL}$ reduction in $L D L-c$ produces a reduction of $20 \%$ in the risk of events related to cardiovascular atherosclerotic disease [35]. This positioning is in accordance to the ACC/AHA 2013 guidelines that recommends to use statins due to the high probability of associated familial hypercholesterolemia [36].

14. It is recommended that dialysis patients do not initiate the use of statins for lack of evidence of benefit in this population, with possible increase in risk of stroke. However, it is recommended not to withdraw the statin in patients with chronic renal failure who are already in use of statin before initiation of dialysis. [LEVEL A]

Summary of evidence:

- The 4D study [37] evaluated 1,255 patients with type 2 diabetes on hemodialysis that were randomized to atorvastatin $20 \mathrm{mg}$ or placebo and followed up for 4 years. The primary endpoint was a composite of death from cardiac causes, nonfatal myocardial infarction, and stroke. There was a $42 \%$ reduction in $L D L-c$ in patients using atorvastatin, however there was no reduction in the primary outcome, and yet it increased the risk of stroke in this group.

- The AURORA study [38] was a randomized, multicenter trial which included 2,776 hemodialysis patients, with ages between 50-80 years, being 27.9\% with diabetes which were treated with rosuvastatin $10 \mathrm{mg} /$ day or placebo during a mean of 3.8 years. The evaluated primary outcome was a composite of nonfatal myocardial infarction, nonfatal stroke, and cardiovascular death. Even with a $43 \%$ reduction in $L D L-c$ in the intervention group, no differences in the primary outcome were observed between groups.

- In respect of patients with chronic renal disease but not in hemodialysis, an analysis of the database of Pravastatin Pooling Project combined results of 3 randomized trials using pravastatin $40 \mathrm{mg}$ vs. placebo [39] including 19,700 patients with chronic 
renal insufficiency (GFR 60-30 $\mathrm{ml} / \mathrm{min} / 1,73 \mathrm{~m}^{2}$ ). This analysis showed significant benefit of treatment in reducing the primary end point of myocardial infarction, coronary death or percutaneous revascularization and total mortality in this particular group of patients. In light of these findings, there are potential benefits for the use of statins in patients in pre-dialysis, so that the present positioning recommends not to remove the statin in patients who were already in use of statin prior to the start of hemodialysis.

\section{It is recommended that patients with heart failure class II to IV do not initiate statin therapy because there is no clear evidence of benefit in this group. [LEVEL A]}

Summary of evidence:

- The randomized, multicenter clinical trial (GISSI-HF) evaluated rosuvastatin $10 \mathrm{mg} /$ day compared to placebo, in 2,285 patients with heart failure at classes II to IV (New York Heart Association), including 26\% of patients with diabetes. There was no benefit over the outcomes: death and hospitalization for cardiovascular causes [40].

- The randomized CORONA study, with 5,011 patients over 60 years showing heart failure class II to $I V$, where 29\% had diabetes, compared the use of rosuvastatin $10 \mathrm{mg}$ versus placebo, assessing the primary endpoint composed of cardiovascular death, acute non-fatal MI and non-fatal stroke during 36 months. Even reducing LDL-c in 45\% there was no significant difference between the groups regarding the primary outcome. The results were extensive to patients with diabetes in the subgroup analysis due to low heterogeneity [41].

16. Patients with type 2 diabetes without a history of cardiovascular events, aged 40-75 years, with 1 or more risk factors (hypertension, retinopathy, micro or macroalbuminuria, smoking or family history of coronary heart disease) should start treatment with statins. [LEVEL A]

Summary of evidence:

- In CARDS study [42], 2,838 patients with diabetes without coronary artery disease prior to age 40 and 75 years and at least 1 additional risk factor (microalbuminuria, retinopathy, hypertension or smoking) were randomized to atorvastatin $10 \mathrm{mg}$ or placebo during a mean follow-up of 3.9 years. The primary outcome was a composite of acute coronary events, coronary revascularization or stroke. The study was terminated prematurely due to efficacy. Atorvastatin $10 \mathrm{mg}$ promoted risk reduction of $37 \%$ (95\% CI -52 to $-17, p=0.001$ ) in the primary endpoint, a reduction of $32 \%$ (95\% CI -45 to $-15, p=0.001$ ) in the risk stroke and a trend of $27 \%$ reduction in total mortality (95\% CI -48 to $1,0 p=0.059$ ). By this study it is estimated that one event is avoided for every 27 patients treated for 4 years.

- The HPS (MRC/BHF Heart Protection Study) substudy [43] randomized 5,963 individuals with diabetes aged 40-80 years, to receive simvastatin $40 \mathrm{mg}$ or placebo. Prespecified subgroup analysis was performed for the outcomes of fatal and non-fatal acute myocardial ilnfarction (AMI) and the first vascular event (major coronary event, stroke, or revascularization). Simvastatin $40 \mathrm{mg}$ reduced these outcomes in 33\% (95\% CI 17-46, $p<0.0003)$, regardless of the level of baseline $L D L-c$. The absolute risk reduction of cardiovascular disease in patients with diabetes without coronary artery disease in HPS was very similar to the CARDS study, confirming the benefit of statins in patients with diabetes in primary prevention in the high-risk group.

\section{Treatment with statins is recommended in patients with cardiovascular risk classified as intermediate or high risk by UKPDS risk engine. [LEVEL B]}

Summary of evidence:

- A meta-analysis of 22 randomized controlled trials evaluated 134,537 subjects at low cardiovascular risk comparing treatment with statins against placebo or less intensive statin therapy for 4.8 years who were subdivided into strata of cardiovascular risk. In stratum 10-20\%/10 years, there were 18\% of patients with diabetes. There was a $21 \%$ reduction in major vascular events for each $39 \mathrm{mg} / \mathrm{dL}$ reduction in $L D L-c$, regardless of age, gender, baseline $L D L-c$ or presence of previous vascular disease. Considering patients without prior vascular disease with risk between 10-20\% in 10 years, there was a 34\% reduction in major vascular events for each mmol reduction in $L D L-c$ in 5 years, with no increase in cancer incidence or mortality from other causes. It is estimated that 15 adverse events could be avoided for each 
$39 \mathrm{mg} / \mathrm{dL}$ reduction of $L D L-c$ in 1000 patients treated for 5 years. The benefit was greater than the incidence of adverse events, even in diabetes patients [44].

\section{This Position Statement did not find evidences} to support the recommendation for treating to $L D L-c$ target of $L D L-c<100 \mathrm{mg} / \mathrm{dL}$ in patients with diabetes without established cardiovascular disease.

After an extensive review, this board did not find any randomized clinical trial indicating that a titrated drug therapy to a specific LDL-c goal does improve cardiovascular outcomes in diabetic subjects. This recommendation is in accordance to the 2013 ACC/AHA guideline on the treatment of blood cholesterol to reduce atherosclerotic cardiovascular risk in adults [36]. Although the American Diabetes Association 2014 position statement still suggests the use of LDL-c targets for patients with diabetes, they also recommend a relative reduction $L D L-c$ of 30-40\% from baseline as an alternative effective goal [45]. The present Position Statement agrees that the use of LDL-c target of $100 \mathrm{mg} / \mathrm{dl}$ may result in under-treatment with statins which have a large body of evidence of event reduction or even overtreatment with non-statin drugs that have no evidence in reducing cardiovascular outcomes despite LDL-c reduction.

19. In patients with intermediate coronary heart risk (10-20\% in 10 years) the calcium score (CAC) can be determined, if available. Patients with CAC scores below 10 may be considered of low cardiovascular risk and should be oriented about changes in lifestyle (healthy diet, weight loss if overweight or obesity and physical activity). Patients with calcium score greater than 10 are considered CAC intermediate-high risk and should be treated with statins. [LEVEL A]

Summary of evidence:

- Meta-analysis of 8 studies [28] including 6,521 patients with diabetes and 5.2 years of follow-up compared mortality and vascular events according to calcium score. Mortality from all causes in patients with CAC score $<10$ compared to patients with CAC score $>10$ was 5.47 times lower (95\% CI 2.59 to 11.53, $p<0.001$ ). For patients with CAC score $<10$, the post-test probability of primary outcome was $1.8 \%$, representing a reduction of $6.8 x$ compared to pre-test probability. The risk of cardiovascular events in patients with a CAC score $<10$ was 9.22 (95\% 2.73 to 31.07 $p=0.005$ ). The prevalence of patients with CAC score $<10$ was $28.5 \%$. Patients with CAC score above 10 have cardiovascular risk of $3 \%$ per year and are considered intermediate to high risk [28].

20. Patients with diabetes and low cardiovascular risk (CHD $<10 \%$ in 10 years) may receive only treatment with changes in lifestyle (healthy diet, weight loss if overweight/obesity and physical activity), however the coronary risk should be re-evaluated yearly. [LEVEL B]

Summary of evidence:

- In the same meta-analysis mentioned in the previous recommendation [28], 24,790 patients were classified as low cardiovascular risk and $7 \%$ had diabetes. In this group, the benefit found was a reduction in 6 major cardiovascular events per 1000 patients treated for 5 years for each reduction of $39 \mathrm{mg} / \mathrm{dL} L D L-c$. By the data of this metanalysis, only 1,2-vascular deaths for every 1000 patients treated with statins for 5 years could be avoided with a reduction of LDL-c of $39 \mathrm{mg} / \mathrm{dL}$. This Position Statement held that, although there was no increase in adverse events in 5 years, the benefits are too faint for a systematic indication of statin for this stratum of risk and a clear isk-benefit study is still needed. This position, however, reiterates the need for annual review of risk stratification for possible re-classification.

\section{Association between statin and fibrate is not} usually recommended for patients with diabetes to reduce cardiovascular risk. However, in the specific situation of men with triglycerides above $204 \mathrm{mg} / \mathrm{dL}$ in association with HDL-c below $34 \mathrm{mg} / \mathrm{dL}$, the combination fenofibrate-statin may be considered. [LEVEL B]

Summary of evidence:

- This is a recommendation based on the analysis of pre-specified subgroup analysis of patients with diabetes from the ACCORD-LIPID study [46], comparing the fenofibrate-simvastatin combination versus simvastatin alone whose trial showed no reduction in the primary outcome. As there was benefit in prespecified subgroup analysis of men 
with triglycerides above $204 \mathrm{mg} / \mathrm{dL}$ and $\mathrm{HDL}-\mathrm{C}$ less than $34 \mathrm{mg} / \mathrm{dL}$, this committee considers that the information is still preliminary and should be viewed with caution.

Algorithm SBD-2014 for the use of statins in patients with diabetes

Based on the currently available literature and after careful review of national and international recommendations by the Expert Group on Diabetes and Cardiovascular Risk of the Brazilian Diabetes Society (SBD), the following algorithm for suggested criteria for statin therapy in patients with diabetes was developed (Figure 2).

Module 4: hypertension

\section{Patients with blood pressure levels greater than} or equal to $140 / 90 \mathrm{mmHg}$ should be considered hypertensive. Patients with levels close to these limits, with no evidence of organ damage, should be reevaluated periodically. It is recommended to measure blood pressure at each routine visit. [LEVEL A]

\section{Summary of evidence:}

- A meta-analysis of 61 observational studies [47] showed that, in the range of 40-69 years old, each increment of $20 \mathrm{mmHg}$ systolic and $10 \mathrm{mmHg}$ diastolic, is associated to a 2-fold increase in incidence in death from stroke and coronary ischemia. Blood pressure above $115 / 75 \mathrm{mmHg}$ is associated with an increased risk for cardiovascular events, mortality and end stage renal disease in patients with diabetes [47].

23. It is recommended that patients with systolic blood pressure between 120-139 $\mathrm{mmHg}$ or diastolic pressure between 80-90 $\mathrm{mmHg}$ should be treated with non-pharmacological measures to control blood pressure. [LEVEL C]

Summary of evidence:

- Because there is no clear evidence of benefit from pharmacological treatment with systolic blood pressure below $140 \mathrm{mmHg}$, only recommended lifestyle modifications are indicated. A randomized clinical trial including 412 subjects [48] compared diets with high, medium and low sodium during 30 consecutive days. The DASH diet (low sodium) resulted in a reduction in average systolic blood pressure of $7.1 \mathrm{mmHg}$ compared to the control diet in individuals without hypertension and of $11.5 \mathrm{mmHg}$ in hypertensive individuals. The diet,

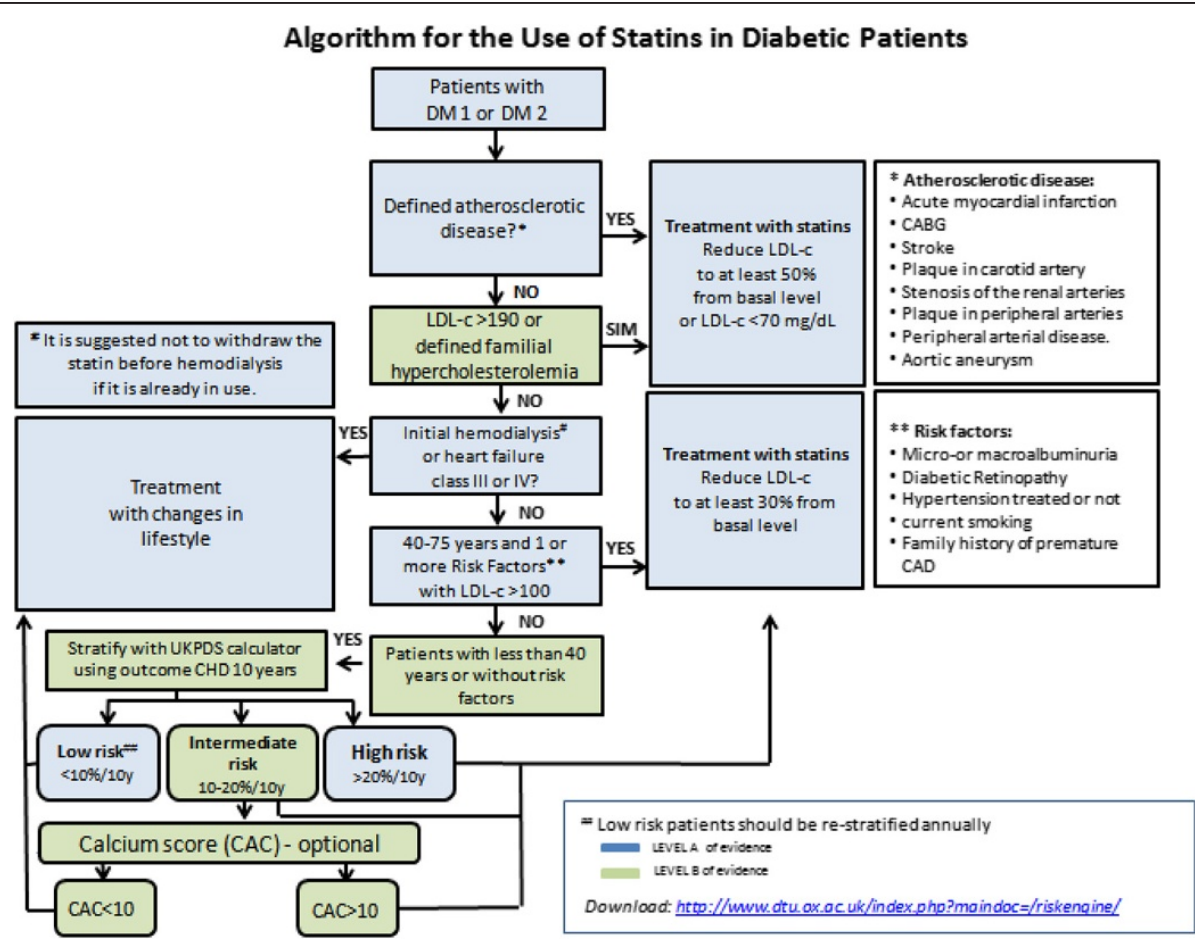

Figure 2 Decision making flow for statin use. 
however, has not been tested in patients with diabetes. Although there are no well-controlled study in the treatment of hypertension with diet and exercise in patients with diabetes studies, the DASH study group showed similar effects with pharmacological treatment in other studies, with results accepted for patients with diabetes, since the risk of adverse effects is negligible. It is recommended that sodium intake should be kept at less than 1,500 mg/day. Excess weight should be controlled. The use of low-fat dairy products, 2-3 daily servings of fruits and vegetables, limited alcohol intake and regular physical activity should be advised.

24. It is recommended that patients with hypertension defined as systolic blood pressure equal to or greater than $140 \mathrm{mmHg}$ or diastolic blood pressure greater than or equal to $90 \mathrm{mmHg}$ receive pharmacological treatment. [LEVEL A]

Summary of evidence:

- A meta-analysis of 31 randomized controlled trials with 73,913 patients with diabetes [49] compared the effect of antihypertensive treatment regimens defined as intensive or less intensive in outcomes such as myocardial infarction and stroke. The meta-analysis found that risk-reductions for stroke and MI are firmly established when comparing antihypertensive agents against placebo. However, when comparing more intensive with less intensive regimen, there was no additional benefit, except a reduction in stroke. Protection is progressive for stroke, but not for acute myocardial infarction. However, no increased incidence of AMI is observed with more intensive blood pressure reductions, suggesting that reductions below to around $130 \mathrm{mmHg}$, can be safely pursued.

25. It is recommended to reduce systolic pressure to below $140 \mathrm{mmHg}$ and diastolic pressure to around $80 \mathrm{mmHg}$, regardless of the presence of micro or macrovascular complications. [LEVEL A]

Summary of evidence:

- The ACCORD BP study [50] was a non-blind arm of the ACCORD trial that directly compared the antihypertensive treatment goals with systolic $B P$ $<120 \mathrm{mmHg}$ vs. Systolic BP $<140 \mathrm{mmHg}$ in 4,733 patients with type 2 diabetes at high cardiovascular risk, with follow-up of 4.7 years. The mean systolic
$B P$ was $119.3 \mathrm{mmHg}$ in the intensive group and $133.5 \mathrm{mmHg}$ in the conventional group. The primary composite outcome (nonfatal MI, nonfatal stroke, and cardiovascular death) was not different between groups. In prespecified secondary outcome, the incidence of stroke was lower in the intensive group $(p<0.001)$. However, the intensive group had a higher rate of adverse effects such as hypotension, hypokalemia, and increased creatinine. Thus, in high-risk patients, it is recommended to reduce systolic BP below $140 \mathrm{mmHg}$ but not below $120 \mathrm{mmHg}$ due to the increased risk of adverse effects.

- A meta-analysis of 5 trials, both observational and randomized clinical trial, including 7,312 patients with diabetes showed that intensive treatment with a reduction in systolic BP to below $130 \mathrm{mmHg}$ vs. reduction of systolic BP to below $140 \mathrm{mmHg}$ showed reduction of the risk of stroke but not in mortality or in acute myocardial infarction [51].

26. Due to the similarity of benefit in cardiovascular outcomes, it is recommended that the decision in the choice of initial drug therapy, including the major classes of antihypertensive drugs, is based on tolerability, cost, and presence of comorbidities. Regarding renal protection, ACE inhibitors and angiotensin receptor blockers are superior. [LEVEL A]

Summary of evidence:

- A meta-analysis of 27 randomized trials with 158,709 patients including 33,395 patients with diabetes, the options of diuretics, calcium dihydropyridine blockers, $A C E$ inhibitors and angiotensin II receptor blockers (ARBs) were equally effective in reducing cardiovascular events in subjects with or without diabetes [52].

- A meta-analysis including 63 randomized controlled trials with 36,917 patients with diabetes compared different antihypertensive drugs versus placebo [53]. $A C E$ inhibitors have consistently shown higher probability in being superior compared to other antihypertensive drugs in relation to renal outcomes, mortality from all causes, onset of dialysis or doubling of creatinine. The meta-analysis also demonstrated superiority of ACE inhibitors in relation to reno-protection, with similar benefit when ARBs are used.

27. In the need of using more than one antihypertensive to achieve target blood pressure, 
it is preferably recommended the association between an angiotensin converting enzyme inhibitor with a dihydropiridin calcium blocker. [LEVEL A]

Summary of evidence:

- The randomized ACCOMPLISH trial [54] included 11,506 patients with high blood pressure and with cardiovascular high risk, including 60\% of patients with diabetes. These patients were randomly assigned to associations to receive benazepril plus amlodipine or benazepril plus hydrochlorothiazide for 36 months. The study showed that the combination benazepril plus amlodipine is superior to the combination of benazepril plus hydrochlorothiazide in reducing the risk of cardiovascular events and mortality (reduction of relative risk of $19.6 \% p<0.001$ ). Subgroup analysis showed that patients with diabetes had similar benefits as the non diabetic patients.

- In a meta-analysis comparing various strategies for antihypertensive treatment including 36,917 patients with diabetes, a total of 640 (1.7\%) patients received combination ACEI-calcium blocker. The combination of ACEI-Calcium Channel Blocker was shown to have the most significant effect in reducing mortality compared to other combinations [53].

28.The use of ACE inhibitors or ARBs in patients with micro or macroalbuminuria is recommended. [LEVEL A]

Summary of evidence:

- In diabetic patients with macroalbuminuria the RENAAL study [55] showed efficacy of losartan compared to placebo in reducing renal outcomes as doubling creatinine, end-stage renal disease or death. Likewise, the IDNT study [56] demonstrated superiority of irbesartan compared to amlodipine in the reduction of the same renal endpoints.

- In patients with microalbuminuria the IRMA-2 study [57] showed progressive reduction of albuminuria with increasing doses of irbesartan.

29. It is recommended to AVOID the combination of ACE inhibitors with ARBs due to greater risk of loss of renal function and hyperkalemia. [LEVEL A]
Summary of evidence:

- The ONTARGET study [58] evaluated the effects of adding an ACE inhibitor (ramipril) to an ARB (telmisartan) in 25,620 patients over 55 years, high-risk, including 9,603 with diabetes during 56 months. Participants were randomized into 3 groups: ramipril, telmisartan and a combination of ramipril with telmisartan. The primary renal outcome was a composite of dialysis, doubling of creatinine and death. The primary outcome was worse with the combination ramipril-telmisartan than with each of antihypertensive monotherapy (HR 1.09 95\% CI: 1.01-1.18 $p=0.037$ ). Thus, the $A C E I-A R B$ combination since is contra-indicated due to its association with worsening of renal outcomes.

30. In pursuit of the goals of blood pressure, other options of combination of 3 or more drugs may be considered, depending on clinical criteria, including ACEI or ARB with amlodipine, thiazide diuretics, beta-blockers, spironolactone, and vasodilators, but with a lower level of evidence. [LEVEL D]

Module 5: antiplatelet therapy

31. The use of acetylsalicylic acid (ASA) (75-162 mg/day) for coronary risk reduction in patients with diabetes and previous cardiovascular events is recommended. [LEVEL A]

Summary of evidence:

- Meta-analysis of the Antithrombotic Trialists (ATT) Collaboration [59] showed that in secondary prevention trials, aspirin compared to placebo resulted in significant reduction of major vascular events (6.7\% vs $8.2 \%$ per year, $p<0,0001)$, with no increase in the risk of hemorrhagic stroke, but significant reduction in total stroke (2.08\% vs $2.54 \%$ per year, $p=0.002)$ and coronary events $(4.3 \% \mathrm{vs}$ $5.3 \%$ per year $p<0.0001$ ).

- The use of ASA for secondary cardiovascular prevention was associated with a significant reduction in mortality in a meta-analysis of 13 studies involving diabetic patients (RR: 0.82, 95\% CI: 0.69 to $0.98, p=0.03$ ) [60].

\section{In patients with diabetes without a history of} cardiovascular events (primary prevention) ASA 
use could be considered only for high-risk patients (>20\% in 10 years). For patients at low or moderate risk, ASA use is not usually recommended since the risk of significant gastrointestinal bleeding may outweight the cardiovascular benefit. [LEVEL A]

Summary of evidence:

- The effect of ASA was reported in only 2 large studies with diabetic patients. The POPADAD study [60] evaluated 176 patients with age above 40 years, with both DM1 and DM2, without prior cardiovascular disease. Patients were randomized to receive ASA $100 \mathrm{mg}$, antioxidant, antioxidant plus ASA or placebo for 5 years. There was no difference in the primary outcome between the groups.

- In the second study, JPAD study [61], researchers examined the efficacy of aspirin in primary prevention in an open study in 2,539 Japanese individuals with diabetes without a history of cardiovascular disease. Patients were randomized to ASA or nothing and were followed for 4.4 years. There was no difference in the total number of events between the group receiving ASA and those who did not receive it (HR 0.80 95\% 0.58 to 1.10). The secondary outcome of coronary and cerebrovascular mortality however, was favorable to the ASA group (HR 0.10 95\% 0.01 to 0.79 ).

- A meta-analysis by the Trialists (ATT) [59] including 6 large studies with ASA in primary prevention in the general population including 95,000 individuals and 4,000 with diabetes, showed that ASA reduces by 12\% (RR 0.88, 95\% 0.82 to 0.94$)$ the risk of vascular events, with the largest reduction for nonfatal MI, with little effect on coronary death and a relative increase in the risk of hemorrhagic stroke (32\%). The effect was similar in the subgroup of patients with diabetes.

- In another meta-analysis [62] only with diabetic patients, including POPADAD and JPAD studies, showed that ASA was associated with non-significant $9 \%$ reduction in risk of coronary events and $10 \%$ in stroke.

- A meta-analysis that evaluated the use of low-dose aspirin in 9 studies (observational and randomized clinical trials) in 11,787 diabetic patients also showed no significant benefit (9\% reduction) in relation to coronary events (95\% CI 0.79 - 1.05) as compared to AVC (non-significant reduction of 10\% (95\% CI 0.711.13) [63]. Similar results were found in 2 other meta-analysis [64,65]. In another meta-analysis in general population [64], ASA reduced risk of MI only in men (relative risk, 0.57 [95\% CI 0.34 to 0.94]).

- The absolute risk of hemorrhagic stroke with low-dose aspirin in the general population is 1:10,000 people annually [66]. In relation to gastro-intestinal bleeding, the absolute risk of gastrointestinal bleeding with aspirin in middle-aged adults is 3 per 1000 per year [63]. Patients with diabetes have a relative increase of 55\% in the risk of bleeding (95\% CI 1.113 to 2.14) compared to patients without diabetes, observed in meta-analysis of 6 studies by Trialists in primary prevention [59]. The combined use of proton pump blockers can reduce this risk [67].

\section{In patients with defined cardiovascular disease and documented allergy to ASA, clopidogrel may be used. [LEVEL C]}

Summary of evidence:

- The CAPRIE study [68] was a randomized double-blind clinical trial that compared the relative efficacy of clopidogrel $75 \mathrm{mg}$ compared to ASA $325 \mathrm{mg}$ in reducing the primary composite end point of ischemic stroke, myocardial infarction or vascular death in patients with ischemic stroke, $r$ acute myocardial infarction and recent peripheral vascular insufficiency for a follow-up of 1-3 years. There were 19,185 patients included being 20\% of diabetic patients. The study showed superiority of clopidogrel compared with ASA in preventing the primary outcome (Relative risk reduction of $8.7 \%$ in favour of clopidogrel (95\% CI 0.3-16.5) with a similar safety profile. Data for diabetic patiets are indirect.

\section{In patients with diabetes presenting with acute coronary syndrome (ACS) it is} recommended the dual antiplatelet treatment with aspirin associated with a P2Y12 receptor antagonist for 1 year after the acute event. Data from clinical trials indicate that the benefit is greater with prasugrel and ticagrelor compared to clopidogrel in the general population with ACS. In a subgroup analysis of patients with diabetes, prasugrel was superior to clopidogrel in patients with ACS undergoing PCI.

[LEVEL B] 
Summary of evidence:

- The results of five randomized trials that compared the combination of ASA plus of P2Y12 receptor antagonist with ASA alone are consistent in showing greater benefit in reducing cardiovascular outcomes with the combination. The studies, however, were not performed exclusively in patients with diabetes. Thus, there is a limitation for the interpretation of these results. However, this committee recommends the use of this combination in patients with diabetes. The evidence supports the use of clopidogrel and ticagrelor when no percutaneous coronary intervention (PCI) is performed, and clopidogrel, prasugrel or ticagrelor when PCI is performed [69-73].

- The TRITON-TIMI 38 study compared prasugrel with clopidogrel in 13,608 patients using aspirin after percutaneous intervention. A prespecified subgroup analysis in 3,146 patients with diabetes showed a reduction of $30 \%$ (HR $0.795 \%$ CI 0.58 to 0.85 , $p<0.001)$ in the primary endpoint with prasugrel compared to clopidogrel. No significant interaction effect between the treatment and the presence of diabetes, indicating that the data can be extended to diabetic patients [73]. As this is a result of a substudy these results are yet to be confirmed for patients with diabetes.

Module 6: myocardial revascularization

35. It is recommended to consider coronary artery bypass graft (CABG) in the following situations [LEVEL B]:

- Myocardial ischemia symptoms not controlled by medical treatment.

- Suspected extensive myocardial ischemia.

- Suspected ischemia with left ventricular dysfunction and myocardial viability.

- Obstruction of greater than 50\% in the left main coronary artery.

Summary of evidence:

- The objectives of myocardial revascularization (MR) are to reduce long-term mortality and improve symptoms and quality of life in patients not well controlled with optimal medical therapy. Patients with diabetes and coronary artery disease have higher long-term mortality compared to patients without diabetes, regardless of treatment strategy [74]. Just as for patients without diabetes, the best criterion for decision MR in patients with diabetes is the clinical assessment, considering the presence of myocardial ischemia (symptoms or evidence of complementary tests), evaluation of coronary anatomy and left ventricular systolic function. Indications for $M R$ in patients with diabetes are similar to those for patients without diabetes, respecting the existing guidelines [75-77].

36. Clinical treatment is recommended as the initial strategy in cases of chronic stable coronary artery disease with preserved ventricular function, controlled symptoms, evidence of myocardial ischemia and coronary anatomy without high-risk criteria. [LEVEL B]

Summary of evidence:

- The COURAGE study [78] randomized 2,287 patients with chronic CAD to receive optimal medical therapy or angioplasty with stent associated with clinical treatment. In the subgroup of 766 patients with diabetes there was no difference between groups with respect to the combined endpoint of mortality and nonfatal myocardial infarction (HR: 0.99, 95\% CI 0.73 to 1.32).

Importantly, patients with more severe angina functional class IV (CCS IV), heart failure (HF), ejection fraction $(L V E F)<30 \%$, recent myocardial revascularization and evidence of ischemia at high risk were excluded from the study.

- In BARI $2 D$ study $[79,80]$ authors randomized 2,368 patients with type 2 diabetes and chronic coronary artery disease to initial strategy of optimal medical therapy or medical treatment with percutaneous or surgical revascularization. There was no difference between groups in relation to survival in a follow-up of 5 years (87.8\% in the medical therapy group vs. $88.3 \%$ in the revascularized group, $p=0.97$ ). However, in patients undergoing surgical revascularization, there was a lower rate of cardiovascular events (death, MI, or stroke) compared to patients in the clinical treatment $(22.4 \%$ vs $30.5 \%, p=0.01$, respectively). This study also excluded patients with lesions of the left main coronary artery and HF patients.

37. In patients with obstruction in more than one arterial territory with indication for CABG, 


\section{surgery should be the preferred strategy in relation to angioplasty, provided that the anatomy is favorable to the surgical procedure. [LEVEL A]}

Summary of evidence:

- The BARI study compared surgical Myocardial Revascularization with balloon angioplasty in patients with chronic coronary artery disease, and in the subgroup of patients with diabetes, survival was higher in the surgical group after a 5 to 10 years follow-up $[79,80]$.

- A meta-analysis using individual data from 7,812 patients showed a $30 \%$ reduction in mortality in the subgroup of 1,233 patients with diabetes undergoing CABG [81].

- The SYNTAX study subdivided the groups in relation to the anatomical complexity, developing the SYNTAX score [82]. On this score, patients with low anatomical complexity (SYNTAX score $\leq 22$ ) had the same morbidity and mortality during follow-up.

However, in the subgroup of patients with anatomically complex lesions (high SYNTAX score 233) showed a higher mortality with angioplasty compared to surgery $(13.5 \%$ vs $4.1 \%, p=0.04$, respectively) [82]. In the 5 years follow-up these patients confirmed the greater number of cardiovascular events in the angioplasty group (46.5\% vs. $29 \%$; $p<0.001)$ in patients with high SYNTAX [83] score. In this analysis there was a trend toward lower mortality in the CABG group, but no statistically significant difference $(p=0.065)$ [84].

- A subanalysis of the same study (SYNTAX) [82] including 452 patients with diabetes, in which it was compared surgery vs. stent angioplasty, patients undergoing angioplasty with pharmacological stent and lesion of the left main coronary artery or three-vessel disease presented a higher rate of cardiovascular events at one year than those who underwent surgical revascularization (26\% vs. $14.2 \%$ respectively, $p=0.003$ ).

- The FREEDOM study [85] randomized 1,900 patients with diabetes and at least bi-arterial lesions (excluding injury in left main coronary artery trunk) for surgical or percutaneous revascularization with stent drug (sirolimus and paclitaxel). After five years follow-up, patients who underwent surgery had lower overall mortality (10.9 vs 16.3\%; $p=0.049$, respectively) and lower incidence of AMI (6 vs. 13\%, $9 \%, p<0.001)$ than those who underwent angioplasty. It should be emphasized that these patients were not subdivided in relation to its anatomical complexity [85]. Therefore, for multi-arterial patients with indication for $C A B G$, surgery should be the preferred strategy in relation to angioplasty, provided the anatomy is favorable to the surgical procedure and the surgical risk be acceptable.

\section{In patients with diabetes and clinical indication for percutaneous myocardial revascularization, we suggest the use of pharmacological stent, provided there is no contraindication to double therapy of anti-platelet aggregation for a mini- mum period of one year. [LEVEL B]}

\section{Summary of evidence:}

- Patients with diabetes treated with drug-eluting stents have a lower rate of need for repeat revascularization than patients treated with non-drug-eluting stents [86,87]. Following five years of ARTS I and II studies [85,88], patients with diabetes undergoing angioplasty with drug eluting stents with sirolimus had a lower rate of AMI and less need for revascularization than patients who received non-pharmacological stent (4,8\% vs. $11 \%$; 0.04 and $p=33.2 \%$ vs. $43.7 \%$; $p=0.02$, respectively).

\section{Competing interests}

Marcello Casaccia Bertoluci, The author declares no competing interest. Augusto Pimazoni-Netto, Sanofi, Becton, Dickinson and Company. Antonio Carlos Pires, Sanofi, BMS, Astra Zeneca, MSD. Antonio Eduardo Pesaro, The author declares no competing interest. Beatriz D. Schaan, The author declares no competing interest. Bruno Caramelli, The author declares no competing interest. Carisi Anne Polanczyk, The author declares no competing interest. Carlos Vicente Serrano Júnior, Novartis, MSD, Boehringer. Danielle M. Gualandro, The author declares no competing interest. Domingos Augusto Malerbi, Sanofi. Emilio Moriguchi, Pfizer, Biolab, Daiichi-Sankyo, MSD. Flavio Antonio de Oliveira Borelli, The author declares no competing interest. João Eduardo Nunes Salles, Aché, Abbott, Astra Zeneca, BMS, Lilly, Jansen, Novartis, Sanofi. José Mariani Júnior, The author declares no competing interest. Luis Eduardo Rohde, The author declares no competing interest. Luis H. Canani, Abbott, BMS, Lylly, MSD, Novo Nordisk, Pfizer, Sanofi, MannKind, GSK, Roche, Boehringer. Luiz Antonio Machado Cesar, Servier. Marcos Tambascia, The author declares no competing interest. Maria Tereza Zanella, Novo Nordisk, Boehringer, Abbott, Astra Zeneca. Miguel Gus, The author declares no competing interest. Rafael Selbach Scheffel, The author declares no competing interest. Raul Dias dos Santos, Amgen, Aegerion, Astra Zeneca, Boehringer, BMS, Biolab, Genzyme, Pfizer, Novo-Nordisk, Novartis, MSD, Sanofi/Regeneron and Nestle.

\section{Authors' contributions}

All authors had full participation in the search for references, in the development of the contents of this Position Statement and also in the peer review procedure of the final text. $\mathrm{MCB}^{1}$ acted as the Chief Editor. $\mathrm{APN}^{2}$ was responsible for the English translation and for the overall editorial coordination. All authors read and approved the final manuscript.

\section{Author details}

'Faculdade de Medicina da Universidade Federal do Rio Grande do Sul, Porto Alegre, Brazil. ${ }^{2}$ Universidade Federal de São Paulo, São Paulo, Brazil. 
${ }^{3}$ Faculdade Estadual de Medicina de São José do Rio Preto, São Paulo, Brazil. ${ }^{4}$ Hospital Albert Einstein, São Paulo, Brazil. ${ }^{5}$ Faculdade de Medicina da Universidade de São Paulo, São Paulo, Brazil. ' ${ }^{6}$ Sociedade Brasileira de Cardiologia, São Paulo, Brazil. ${ }^{7}$ Sociedade Brasileira de Diabetes, São Paulo, Brazil. ${ }^{8}$ Universidade de São Paulo, São Paulo, Brazil. ${ }^{9}$ Faculdade de Ciências Médicas da Santa Casa de São Paulo, São Paulo, Brazil. ${ }^{10}$ Faculdade de Ciências Médicas da Universidade de Campinas, Campinas, SP, Brazil.

${ }^{11}$ Hospital de Clínicas de Porto Alegre, Porto Alegre, RS, Brazil.

Received: 28 March 2014 Accepted: 7 May 2014

Published: 20 May 2014

\section{References}

1. The Diabetes Control and Complications Trial Research Group: The effect of intensive treatment of diabetes on the development and progression of long-term complications in insulin-dependent diabetes mellitus. N Engl J Med 1993, 329(14):977-986

2. UK Prospective Diabetes Study (UKPDS) Group: Intensive blood-glucose control with sulphonylureas or insulin compared with conventional treatment and risk of complications in patients with type 2 diabetes (UKPDS 33). Lancet 1998, 352(9131):837-853.

3. UK Prospective Diabetes Study (UKPDS) Group: Effect of intensive bloodglucose control with metformin on complications in overweight patients with type 2 diabetes (UKPDS 34). Lancet 1998, 352(9131):854-865.

4. Action to Control Cardiovascular Risk in Diabetes Study Group, Gerstein HC, Miller ME, Byington RP, Goff DC Jr, Bigger JT, Buse JB, Cushman WC, Genuth S, Ismail-Beigi F, Grimm RH Jr, Probstfield JL, Simons-Morton DG, Friedewald WT: Effects of intensive glucose lowering in type 2 diabetes. N Engl J Med 2008, 358(24):2545-2559.

5. Holman RR, Paul SK, Bethel MA, Matthews DR, Neil HA: 10-year follow-up of intensive glucose control in type 2 diabetes. N Engl J Med 2008, 359(15):1577-1589.

6. Ray KK, Seshasai SR, Wijesuriya S, Sivakumaran R, Nethercott S, Preiss D, Erqou S, Sattar N: Effect of intensive control of glucose on cardiovascular outcomes and death in patients with diabetes mellitus: a meta-analysis of randomised controlled trials. Lancet 2009, 373(9677):1765-1772.

7. ADVANCE Collaborative Group, Patel A, MacMahon S, Chalmers J, Neal B, Billot L, Woodward M, Marre M, Cooper M, Glasziou P, Grobbee D, Hamet P, Harrap S, Heller S, Liu L, Mancia G, Mogensen CE, Pan C, Poulter N, Rodgers A, Williams B, Bompoint S, de Galan BE, Joshi R, Travert F: Intensive blood glucose control and vascular outcomes in patients with type 2 diabetes. $N$ Engl J Med 2008, 358(24):2560-2572.

8. The action to control cardiovascular risk in diabetes study group: Effects of intensive glucose lowering in type 2 diabetes. NEJM 2008, 358:2545-2559.

9. Duckworth W, Abraira C, Moritz T, Reda D, Emanuele N, Reaven PD, Zieve FJ, Marks J, Davis SN, Hayward R, Warren SR, Goldman S, McCarren M, Vitek ME, Henderson WG, Huang GD, VADT Investigators: Glucose Control and Vascular Complications in Veterans with Type 2 Diabetes. N Eng/ J Med 2009, 360 (2):129-139.

10. Control Group, Turnbull FM, Abraira C, Anderson RJ, Byington RP, Chalmers JP, Duckworth WC, Evans GW, Gerstein HC, Holman RR, Moritz TE, Neal BC, Ninomiya T, Patel AA, Paul SK, Travert F, Woodward M: Intensive glucose control and macrovascular outcomes in type 2 diabetes. Diabetologia 2009, 52(11):2288-98.11.

11. American Diabetes Association: Standards of medical care in diabetes-2014. Diabetes Care 2014, 37(Suppl 1):S14-S80.

12. Yudkin JS, Richter B, Gale EA: Intensified glucose lowering in type 2 diabetes: time for a reappraisal. Diabetologia 2010, 53(10):2079-2085.

13. Narayan KMV, Zhang P, Kanaya AM, Williams DE, Engelgau MM, Imperatore G, Ramachandran A: Diabetes: The Pandemic and Potential Solutions. In Source: Disease Control Priorities in Developing Countries. 2nd edition. Edited by Jamison DT, Breman JG, Measham AR, Alleyne G, Claeson M, Evans DB, Jha P, Mills A, Musgrove P. Washington (DC): World Bank; 2006. Chapter 30.

14. Raz I, Riddle MC, Rosenstock J, Buse JB, Inzucchi SE, Home PD, Del Prato S, Ferrannini E, Chan JC, Leiter LA, Leroith D, Defronzo R, Cefalu WT: Personalized management of hyperglycemia in type 2 diabetes: reflections from a Diabetes Care Editors' Expert Forum. Diabetes Care 2013, 36(6):1779-1788.
15. Malmberg K, DIGAMI (Diabetes Mellitus, Insulin Glucose Infusion in Acute Myocardial Infarction) Study Group: Prospective randomised study of intensive insulin treatment on long term survival after acute myocardial infarction in patients with diabetes mellitus. BMJ 1997, 314(7093):1512-1515.

16. Malmberg K, Rydén L, Wedel H, Birkeland K, Bootsma A, Dickstein K, Efendic S, Fisher M, Hamsten A, Herlitz J, Hildebrandt P, MacLeod K, Laakso M, Torp-Pedersen C, Waldenström A, DIGAMI 2 Investigators: Intense metabolic control by means of insulin in patients with diabetes mellitus and acute myocardial infarction (DIGAMI 2): effects on mortality and morbidity. Eur Heart J 2005, 26(7):650-661.

17. Cheung NW, Wong WW, McLean M: The hyperglycemia: intensive insulin infusion in infarction (HI-5) study: a randomized controlled trial of insulin infusion therapy for myocardial infarction. Diabetes Care 2006, 29(4):765-770.

18. Ledur P, Almeida L, Pellanda LC, Schaan BD: Clinical features and outcomes in patients with diabetes mellitus undergoing coronary artery bypass graft in a reference center in southern Brazil. Rev Assoc Med Bras 2011, 57(2):200-204.

19. Jones KW, Cain AS, Mitchell JH, Millar RC, Rimmasch HL, French TK, Abbate SL, Roberts CA, Stevenson SR, Marshall D, Lappé DL: Hyperglycemia predicts mortality after CABG: postoperative hyperglycemia predicts dramatic increases in mortality after coronary artery bypass graft surgery. J Diabetes Complications 2008, 22(6):365-367.

20. Furnary AP, Zerr KJ, Grunkemeier GL, Starr A: Continuous intravenous insulin infusion reduces the incidence of deep sternal wound infection in diabetic patients after cardiac surgical procedures. Ann Thorac Surg 1999, 67(2):352-360. discussion 60-2.

21. Furnary AP, Gao G, Grunkemeier GL, Wu Y, Zerr KJ, Bookin SO, Floten HS, Starr A: Continuous insulin infusion reduces mortality in patients with diabetes undergoing coronary artery bypass grafting. J Thorac Cardiovasc Surg 2003, 125(5):1007-1021.

22. van den Berghe $G$, Wouters $P$, Weekers F, Verwaest $C$, Bruyninckx F, Schetz M, Vlasselaers D, Ferdinande P, Lauwers P, Bouillon R: Intensive insulin therapy in critically ill patients. N Engl J Med 2001, 345(19):1359-1367.

23. NICE-SUGAR Study Investigators, Finfer S, Chittock DR, Su SY, Blair D, Foster D, Dhingra V, Bellomo R, Cook D, Dodek P, Henderson WR, Hébert PC, Heritier S, Heyland DK, McArthur C, McDonald E, Mitchell I, Myburgh JA, Norton R, Potter J, Robinson BG, Ronco Jj: Intensive versus conventional glucose control in critically ill patients. N Engl J Med 2009, 360(13):1283-1297.

24. Griesdale DE, de Souza RJ, van Dam RM, Heyland DK, Cook DJ, Malhotra A, Dhaliwal R, Henderson WR, Chittock DR, Finfer S, Talmor D: Intensive insulin therapy and mortality among critically ill patients: a meta-analysis including NICE-SUGAR study data. CMAJ 2009, 180(8):821-827. 12.

25. Lazar HL, McDonnell MM, Chipkin S, Fitzgerald C, Bliss C, Cabral H: Effects of aggressive versus moderate glycemic control on clinical outcomes in diabetic coronary artery bypass graft patients. Ann Surg 2011, 254(3):458-463. discussion 63-4.

26. Stevens RJ1, Kothari V, Adler Al, Stratton IM, United Kingdom Prospective Diabetes Study (UKPDS) Group: The UKPDS risk engine: a model for the risk of coronary heart disease in typell Diabetes. (UKPDS 56). Clin Sci 2001, 101:671-679.

27. Chamnan P, Simmons RK, Sharp SJ, Griffin SJ, Wareham NJ: Cardiovascular risk assessment scores for people with diabetes: a systematic review. Diabetologia 2009, 52(10):2001-2014. Epub 2009 Jul 24.

28. Kramer CK, Zinman B, Gross JL, Canani LH, Rodrigues TC, Azevedo MJ, Retnakaran $\mathrm{R}$ : Coronary artery calcium score prediction of all cause mortality and cardiovascular events in people with type 2 diabetes: A systematic review and meta-analysis. BMJ 2013, 346:f1654.

29. Blaha MJ: Associations between C-reactive protein, coronary artery calcium and cardiovascular events: implications for the JUPITER population from MESA, a population-based cohort. Lancet 2011, 378:684-692.

30. Young LH, Wackers FJ, Chyun DA, Davey JA, Barrett EJ, Taillefer R, Heller GV, Iskandrian AE, Wittlin SD, Filipchuk N, Ratner RE, Inzucchi SE, DIAD Investigators: Cardiac outcomes after screening for asymptomatic coronary artery disease in patients with type2 diabetes: the DIAD study: a randomized controlled trial. JAMA 2009, 301(15):1547-1555.

31. Bansal S, Wackers FJ, Inzucchi SE, Chyun DA, Davey JA, Staib LH, Young LH, DIAD Study Investigators: Five-year outcomes in high-risk participants in 
the detection of ischemia in asymptomatic diabetics (DIAD) study: a post hoc analysis. Diabetes Care 2011, 34(1):204-209.

32. Cholesterol Treatment Trialist (CTT) Collaborators: Efficacy of cholesterollowering therapy in 18.686 people with diabetes in 14 randomised trials of statins: a meta-analysis. Lancet 2008, 371:117-125.

33. Cholesterol Treatment Trialist (CTT) Collaboration: Efficacy and safety of more intensive lowering of LDL cholesterol: a metanalysis of data from 170.000 participants in 26 randomised trials. Lancet 2010 376:1670-1681.

34. Shepherd J, Shepherd J, Barter P, Carmena R, Deedwania P, Fruchart JC, Haffner S, Hsia J, Breazna A, LaRosa J, Grundy S, Waters D: Effect of lowering LDL cholesterol substantially below currently recommended levels in patients with coronary heart disease and Diabetes, The treating to New Targets (TNT) study. Diabetes Care 2006, 29:1220-1226.

35. Goff DC Jr, Lloyd-Jones DM, Bennett G, O'Donnell CJ, Coady S, Robinson J, D'Agostino RB Sr, Schwartz JS, Gibbons R, Shero ST, Greenland P, Smith SC Jr, Lackland DT, Sorlie P, Levy D, Stone NJ, Wilson PW: 2013 ACC/AHA Guideline on the Assessment of Cardiovascular Risk: A Report of the American College of Cardiology/American Heart Association Task Force on Practice Guidelines. J Am Coll Cardiol 2013. doi:10.1016/j.jacc.2013.11.005. [Epub ahead of print].

36. Stone NJ, Robinson J, Lichtenstein AH, Bairey Merz CN, Lloyd-Jones DM, Blum CB, McBride P, Eckel RH, Schwartz JS, Goldberg AC, Shero ST, Gordon D, Smith SC Jr, Levy D, Watson K, Wilson PW: 2013 ACC/AHA Guideline on the Treatment of Blood Cholesterol to Reduce Atherosclerotic Cardiovascular Risk in Adults: A Report of the American College of Cardiology/American Heart Association Task Force on Practice Guidelines. J Am Coll Cardio/ 2013. doi:10.1016/j.jacc.2013.11.002. [Epub ahead of print].

37. Wanner C, Krane V, März W, Olschewski M, Mann JF, Ruf G, Ritz E, German Diabetes and Dialysis Study Investigators: Atorvastatin in patients with type 2 diabetes mellitus undergoing hemodialysis. N Engl J Med 2005, 353:238-248.

38. Fellström BC, Jardine AG, Schmieder RE, Holdaas H, Bannister K, Beutler J, Chae DW, Chevaile A, Cobbe SM, Grönhagen-Riska C, De Lima JJ, Lins R, Mayer G, McMahon AW, Parving HH, Remuzzi G, Samuelsson O, Sonkodi S, Sci D, Süleymanlar G, Tsakiris D, Tesar V, Todorov V, Wiecek A, Wüthrich RP, Gottlow M, Johnsson E, Zannad F, AURORA Study Group: Rosuvastatin and cardiovascular events in patients undergoing hemodialysis. N Eng J Med 2009, 360(14):1395-1407.

39. Tonelli M, Isles C, Curhan GC, Tonkin A, Pfeffer MA, Shepherd J, Sacks FM, Furberg C, Cobbe SM, Simes J, Craven T, West M: Effect of pravastatin on cardiovascular events in people with chronic kidney disease. Circulation 2004, 110(12):1557-1563.

40. Investigators G-HF: Effect of rosuvastatin in patients with chronic heart failure (the GISSI-HF trial): a randomized, double-blind, placebo-controlled trial. Lancet 2008, 372(9645):1231-1239.

41. Kjekshus J, Apetrei E, Barrios V, Böhm M, Cleland JG, Cornel JH, Dunselman P, Fonseca C, Goudev A, Grande P, Gullestad L, Hjalmarson A, Hradec J, Jánosi A, Kamenský G, Komajda M, Korewicki J, Kuusi T, Mach F, Mareev V, McMurray JJ, Ranjith N, Schaufelberger M, Vanhaecke J, van Veldhuisen DJ, Waagstein F, Wedel H, Wikstrand J, CORONA Group: Rosuvastatin in older patients with Systolic Heart Failure. N Eng J Med 2007, 357:2248-2261.

42. Colhoun HM1, Betteridge DJ, Durrington PN, Hitman GA, Neil HA, Livingstone SJ, Thomason MJ, Mackness MI, Charlton-Menys V, Fuller JH, CARDS investigators: Primary prevention of cardiovascular disease with atorvastatin in type 2 diabetes in the Collaborative Atorvasatin Diabetes Study (CARDS): multicentre randomized placebo-controlled trial. Lancet 2004, 364(9435):685-696

43. Collins R, Armitage J, Parish S, Sleigh P, Peto R, Heart Protection Study Collaborative Group: MRC/BHF Heart Protection Study of cholesterollowering with simvastatin in 5963 people with diabetes: a randomised placebo-controlled trial. Lancet 2003, 361(9374):2005-2016.

44. Cholesterol Treatment Trialists (CTT) Collaborators: The effects of lowering LDL cholesterol with statin therapy in people at low risk of vascular disease: meta-analysis of individual data from 27 randomised trials. Lancet 2012, 380:581-590.

45. American Diabetes Association: Standards of medical care in diabetes 2014. Diabetes Care 2014, 37(1):S14-S79.

46. The Accord Study Group: Effects of combination lipid therapy in type 2 diabetes. NEJM 2010, 362:17.

47. Lewington S, Clarke R, Qizilbash N, Peto R, Collins R, Prospective Studies Collaboration: Age-specific relevance of usual blood pressure to vascular mortality: a meta-analysis of individual data for one million adults in 61 prospective studies. Lancet 2002, 360(9349):1903-1913.

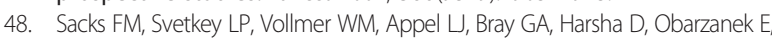
Conlin PR, Miller ER, Simons-Morton DG, Karanja N, Lin PH, DASH-Sodium Collaborative Research Group: Effect on blood pressure of reduced dietary sodium and the Dietary Approaches to Stop Hypertension (DASH) diet. N Eng J Med 2001, 344(1):3-10.

49. Reboldi G, Gentile G, Angeli F, Ambrosio G, Mancia G, Verdecchia P: Effects of intensive blood pressure reduction on myocardial infarction and stroke in diabetes: a meta-analysis in 73,913 patients. J Hypertens 2011, 29:1253-1269

50. The ACCORD Study Group: Effect of intensive blood-pressure control in type 2 diabetes mellitus. NEJM 2010, 362:1575-1585.

51. McBrien K, Rabi DM, Campbell N, Barnieh L, Clement F, Hemmelgarn BR, Tonelli M, Leiter LA, Klarenbach SW, Manns BJ: Intensive and standard blood pressure targets in patients with type 2 diabetes mellitus: a systematic review and meta-analysis. Arch Intern Med 2012, 172(17):1296-1303.

52. Blood Pressure Lowering Treatment Trialists' Collaboration: Blood pressure lowering treatment effects of different blood pressure-lowering regimens on major cardiovascular events in individuals with and without diabetes mellitus. Results of prospectively designed overviews of randomized trials. Arch Intern Med 2005, 165:1410-1419.

53. Wu HY, Huang JW, Lin HJ, Liao WC, Peng YS, Hung KY, Wu KD, Tu YK, Chien KL: Comparative effectiveness of renin-angiotensin system blockers and other anti-hypertensive drugs in patients with diabetes: Systematic Review and Bayesian network meta-analysis. BMJ 2013, 347:66008.

54. Jamerson K, Weber MA, Bakris GL, Dahlöf B, Pitt B, Shi V, Hester A, Gupte J, Gatlin M, Velazquez EJ, ACCOMPLISH Trial Investigators: Benazepril plus Amlodipine or hydrochlorthiazide for hypertension in high-risk patients. N Engl J Med 2008, 359(23):2417-2428.

55. Brenner BM, Cooper ME, de Zeeuw D, Keane WF, Mitch WE, Parving HH, Remuzzi G, Snapinn SM, Zhang Z, Shahinfar S, RENAAL Study Investigators: Effects of losartan on renal and cardiovascular outcomes in patients with type 2 diabetes and nephropathy. N Engl $J$ Med 2001, 345(12):861.

56. Lewis EJ, Hunsicker LG, Clarke WR, Berl T, Pohl MA, Lewis JB, Ritz E, Atkins RC, Rohde R, Raz I, Collaborative Study Group: Renoprotective effect of the angiotensin-receptorantagonist irbesartan in patients with nephropathy due to type 2 diabetes. N Engl J Med 2001, 345:851.

57. Kunz R, Friedrich C, Wolbers M, Mann JFE: Meta-analysis: effect of monotherapy and combination therapy with Inhibitors of the renin-angiotensin system on proteinuria in renal disease. Ann Intern Med 2008, 148(1):30-48

58. Mann JF, Schmieder RE, McQueen M, Dyal L, Schumacher H, Pogue J, Wang X, Maggioni A, Budaj A, Chaithiraphan S, Dickstein K, Keltai M, Metsärinne K, Oto A, Parkhomenko A, Piegas LS, Svendsen TL, Teo KK, Yusuf S, ONTARGET investigators: Renal outcomes with telmisartan, ramipril, or both, in people at high vascular risk (The ONTARGET study): a multicentre, randomised, double-blind, controlled trial. Lancet 2008, 372:547-553.

59. Antithrombotic Trialists' (ATT) Collaboration, Baigent C, Blackwell L, Collins R, Emberson J, Godwin J, Peto R, Buring J, Hennekens C, Kearney P, Meade T, Patrono C, Roncaglioni MC, Zanchetti A: Aspirin in the primary and secondary prevention of vascular disease: collaborative meta-analysis of individual participant data from randomised trials. Lancet 2009, 373(9678):1849-1860.

60. Ogawa H, Nakayama M, Morimoto T, Uemura S, Kanauchi M, Doi N, Jinnouchi H, Sugiyama S, Saito Y: Japanese Primary Prevention of Atherosclerosis With Aspirin for Diabetes (JPAD) Trial Investigators. Low dose aspirin for primary prevention of atherosclerotic events in patients with type 2 diabetes: a randomized controlled trial. JAMA 2008, 300:2134-2141.

61. Belch J, MacCuish A, Campbell I, Cobbe S, Taylor R, Prescott R, Lee R, Bancroft J, MacEwan S, Shepherd J, Macfarlane P, Morris A, Jung R, Kelly C, Connacher A, Peden N, Jamieson A, Matthews D, Leese G, McKnight J, O'Brien I, Semple C, Petrie J, Gordon D, Pringle S, MacWalter R, Prevention of Progression of Arterial Disease and Diabetes Study Group; Diabetes Registry Group; Royal College of Physicians Edinburgh: The prevention of progression of arterial disease and diabetes (POPADAD) trial: factorial 
randomized placebo controlled trial of aspirin and anti-oxidants in patients with diabetes and asymptomatic peripheral arterial disease. BMJ 2008, 337:a1840.

62. Simpson SH, Gamble JM, Mereu L, Chambers T: Effect of aspirin dose on mortality and cardiovascular events in people with diabetes: a metaanalysis. J Gen Intern Med 2011, 26(11):1336-1344.

63. Pignone M, Alberts MJ, Colwell JA, Cushman M, Inzucchi SE, Mukherjee D, Rosenson RS, Williams CD, Wilson PW, Kirkman MS: Aspirin for primary prevention of cardiovascular events in people with diabetes. A position statement of the American Diabetes Association, a scientific atatement of the American Heart Assoiation, and an expert consensus document of the American College of Cardiology Foundation. Diabetes Care 2010, 33(6):1395-1402.

64. De Berardis G, Sacco M, Strippoli GFM, Pellegrini F, Graziano G, Tognoni G, Nicolucci A: Aspirin for primary prevention of cardiovascular events in people with diabetes: meta-analysis of randomized controlled trials. BMJ 2009, 339:b4531.

65. Zhang C, Sun A, Zhang P, Wu C, Zhang S, Fu M, Wang K, Zou Y, Ge J: Aspirin for primary prevention of cardiovascular events in patients with diabetes: a metanalysis. Diabetes Res Clin Pract 2010, 87(2):211-218.

66. He J: Aspirin and risk of hemorrhagic stroke: a meta-analysis of randomized controlled trials. JAMA 1998, 280:1930-1935.

67. Lai KC, Lam SK, Chu KM, Wong BC, Hui WM, Hu WH, Lau GK, Wong WM, Yuen MF, Chan AO, Lai CL, Wong J: Lansoprazole for the prevention of recurrences of ulcer complications for long-term low dose aspirin use. N Engl J Med 2002, 346(26):2033-2038.

68. CAPRIE Steering Committee: A randomised, blinded, trial $\mathrm{f}$ clopidogrel versus aspirin in patients at risk of ischaemic events. Lancet 1996, 348:1329-1339.

69. The Clopidogrel in Unstable Angina to Prevent Recurrent Events Trial Investigators: Effects of clopidogrel in addition to aspirin in patients with acute coronary syndromes without ST-segment elevation. N Engl J Med 2001, 345:494-502.

70. COMMIT (Clopidogrel and metoprolol in myocardial infarction trial) collaborative group, Chen ZM, Jiang LX, Chen YP, Xie JX, Pan HC, Peto R, Collins R, Liu LS: Addition of clopidogrel to aspirin in 45,852 patients with acute myocardial infarction: randomised placebo-controlled trial. Lancet 2005, 366:1607-1621.

71. Sabatine MS, Cannon CP, Gibson CM, López-Sendón JL, Montalescot G, Theroux P, Claeys MJ, Cools F, Hill KA, Skene AM, McCabe CH, Braunwald E, CLARITY-TIMI 28 Investigators: Addition of clopidogrel to aspirin and fibrinolytic therapy for myocardial infarction with ST-segment elevation. N Engl J Med 2005, 352:1179-1189.

72. James S, Angiolillo DJ, Cornel JH, Erlinge D, Husted S, Kontny FK, Maya J, Nicolau JC, Spinar J, Storey RF, Stevens SR, Wallentin L, For the PLATO study group: Ticagrelor vs. clopidogrel in patients with acute coronary syndromes and diabetes: a substudy from the PLATelet inhibition and patient Outcomes (PLATO) trial. Eur Heart J 2010, 32:3006-3016.

73. Wiviott SD1, Braunwald E, McCabe CH, Montalescot G, Ruzyllo W, Gottlieb S, Neumann FJ, Ardissino D, De Servi S, Murphy SA, Riesmeyer J, Weerakkody G, Gibson CM, Antman EM, TRITON-TIMI 38 Investigators: Prasugrel versus clopidogrel in patients with coronary syndromes. N Engl J Med 2007, 357(20):2001-2015.

74. Hueb W, Gersh BJ, Costa F, Lopes N, Soares PR, Dutra P, Jatene F, Pereira AC, Góis AF, Oliveira SA, Ramires JA: Impact of diabetes on five-year outcomes of patients with multivessel coronary artery disease. Ann Thorac Surg 2007, 83(1):93-99.

75. Fihn SD, Gardin JM, Abrams J, Berra K, Blankenship JC, Dallas AP, Douglas PS, Foody JM, Gerber TC, Hinderliter AL, King SB 3rd, Kligfield PD, Krumholz HM, Kwong RY, Lim MJ, Linderbaum JA, Mack MJ, Munger MA, Prager RL, Sabik JF, Shaw LJ, Sikkema JD, Smith CR Jr, Smith SC Jr, Spertus JA, Williams SV, Anderson JL, American College of Cardiology Foundation/American Heart Association Task Force: 2012 ACCF/AHA/ACP/AATS/PCNA/SCAI/STS guideline for the diagnosis and management of patients with stable ischemic heart disease: a report of the American College of Cardiology Foundation/American Heart Association task force on practice guidelines, and the American College of Physicians, American Association for Thoracic Surgery, Preventive Cardiovascular Nurses Association, Society for Cardiovascular Angiography and Interventions, and Society of Thoracic Surgeons. Circulation 2012, 126(25):e354-e471.

76. MEMBERS WC, Staff Pa, Foundation ACoC, Association ACoCFAH, Association $\mathrm{AH}$ : 2012 ACCF/AHA focused update incorporated into the
ACCF/AHA 2007 guidelines for the management of patients with unstable angina/non-ST-elevation myocardial infarction: a report of the American college of cardiology foundation/American heart association task force on practice guidelines. Circulation 2013, 127(23):e663-e828.

77. O'Gara PT, Kushner FG, Ascheim DD, Casey DE, Chung MK, de Lemos JA, Ettinger SM, Fang JC, Fesmire FM, Franklin BA, Granger CB, Krumholz HM, Linderbaum JA, Morrow DA, Newby LK, Ornato JP, Ou N, Radford MJ, Tamis-Holland JE, Tommaso CL, Tracy CM, Woo YJ, Zhao DX, Anderson JL, Jacobs AK, Halperin JL, Albert NM, Brindis RG, Creager MA, DeMets D, American College of Cardiology Foundation/American Heart Association Task Force on Practice Guidelines, et al: 2013 ACCF/AHA guideline for the management of ST-elevation myocardial infarction: a report of the American College of Cardiology Foundation/American Heart Association Task Force on Practice Guidelines. Circulation 2013, 127(4):e362-e425.

78. Boden WE, O'Rourke RA, Teo KK, Hartigan PM, Maron DJ, Kostuk WJ, Knudtson M, Dada M, Casperson P, Harris CL, Chaitman BR, Shaw L, Gosselin G, Nawaz S, Title LM, Gau G, Blaustein AS, Booth DC, Bates ER, Spertus JA, Berman DS, Mancini GB, Weintraub WS, COURAGE Trial Research Group: Optimal medical therapy with or without PCI for stable coronary disease. N Engl J Med 2007, 356(15):1503-1516

79. The Bypass Angioplasty Revascularization Investigation (BARI) Investigators: Comparison of coronary bypass surgery with angioplasty in patients with multivessel disease. N Engl J Med 1996, 335(4):217-225

80. Investigators B: The final 10-year follow-up results from the BARI randomized trial. J Am Coll Cardiol 2007, 49(15):1600-1606.

81. Hlatky MA, Boothroyd DB, Bravata DM, Boersma E, Booth J, Brooks MM, Carrié D, Clayton TC, Danchin N, Flather M, Hamm CW, Hueb WA, Kähler J, Kelsey SF, King SB, Kosinski AS, Lopes N, McDonald KM, Rodriguez A, Serruys P, Sigwart U, Stables RH, Owens DK, Pocock SJ: Coronary artery bypass surgery compared with percutaneous coronary interventions for multivessel disease: a collaborative analysis of individual patient data from ten randomised trials. Lancet 2009, 373(9670):1190-1197.

82. Sianos G, Morel MA, Kappetein AP, Morice MC, Colombo A, Dawkins K, van den Brand M, Van Dyck N, Russell ME, Mohr FW, Serruys PW: The SYNTAX score: an angiographic tool grading the complexity of coronary artery disease. Eurointervention 2005, 1:219-227.

83. Mohr FW, Morice MC, Kappetein AP, Feldman TE, Ståhle E, Colombo A, Mack MJ, Holmes DR Jr, Morel MA, Van Dyck N, Houle VM, Dawkins KD, Serruys PW: Coronary artery bypass graft surgery versus percutaneous coronary intervention in patients with three-vessel disease and left-main coronary disease: 5-year follow-up of the randomized, clinical SYNTAX trial. Lancet 2013, 381:629-638.

84. Banning AP1, Westaby S, Morice MC, Kappetein AP, Mohr FW, Berti S, Glauber M, Kellett MA, Kramer RS, Leadley K, Dawkins KD, Serruys PW: Diabetic and nondiabetic patients with left main and/or 3-vessel coronary artery disease: comparison of outcomes with cardiac surgery and paclitaxel-eluting stents. J Am Coll Cardiol 2010, 55(11):1067-1075.

85. Farkouh ME, Domanski M, Sleeper LA, Siami FS, Dangas G, Mack M, Yang M, Cohen DJ, Rosenberg Y, Solomon SD, Desai AS, Gersh BJ, Magnuson EA, Lansky A, Boineau R, Weinberger J, Ramanathan K, Sousa JE, Rankin J, Bhargava B, Buse J, Hueb W, Smith CR, Muratov V, Bansilal S, King S III, Bertrand M, Fuster $V$, FREEDOM Trial Investigators: Strategies for multivessel revascularization in patients with diabetes. N Engl J Med 2012, 367(25):2375-2384.

86. Kappetein AP1, Head SJ, Morice MC, Banning AP, Serruys PW, Mohr FW, Dawkins KD, Mack MJ, SYNTAX Investigators: Treatment of complex coronary artery disease in patients with diabetes: 5-year results comparing outcomes of bypass surgery and percutaneous coronary intervention in the SYNTAX trial. Eur J Cardiothorac Surg 2013, 43(5):1006-1013.

87. Stettler C, Allemann S, Wandel S, Kastrati A, Morice MC, Schömig A, Pfisterer ME, Stone GW, Leon MB, de Lezo JS, Goy JJ, Park SJ, Sabaté M, Suttorp MJ, Kelbaek H, Spaulding C, Menichelli M, Vermeersch P, Dirksen MT, Cervinka P, De Carlo M, Erglis A, Chechi T, Ortolani P, Schalij MJ, Diem P, Meier B, Windecker $S$, Jüni P: Drug eluting and bare metal stents in people with 
and without diabetes: collaborative network meta-analysis. BMJ 2008, 337:a1331.

88. Onuma Y, Wykrzykowska JJ, Garg S, Vranckx P, Serruys PW, Investigators Alal: 5-Year follow-up of coronary revascualarization in diabetic patients with multivessel coronary artery disease: insights from ARTS (arterial revascularization therapy study)-II and ARTS-I trials. JACC Cardiovasc Interv 2011, 4(3):317-323.

doi:10.1186/1758-5996-6-58

Cite this article as: Bertoluci et al: Diabetes and cardiovascular disease:

from evidence to clinical practice - position statement 2014 of Brazilian Diabetes Society. Diabetology \& Metabolic Syndrome 2014 6:58.

\section{Submit your next manuscript to BioMed Central and take full advantage of:}

- Convenient online submission

- Thorough peer review

- No space constraints or color figure charges

- Immediate publication on acceptance

- Inclusion in PubMed, CAS, Scopus and Google Scholar

- Research which is freely available for redistribution 